\title{
A Techno-Economic Assessment of 5G Networks with Passive Optical Network-Based Mobile Backhaul and Hybrid Fiber- Copper Fronthaul
}

\author{
André L. P. Fernandes ${ }^{1}$, Fabricio S. Farias ${ }^{2}$, Aline A. Ohashi ${ }^{1}$, Marcos V. P. \\ Oliveira $^{2}$, João C. W. A. Costa ${ }^{1}$ \\ ${ }^{1}$ Programa de pós-graduação em engenharia elétrica (PPGEE) \\ Universidade Federal do Pará (UFPA) - Belém - PA - Brazil \\ ${ }^{2}$ Faculdade de Sistemas de Informação - Universidade Federal do Pará (UFPA)- \\ Cametá - PA - Brazil \\ andre.lucaspinho@gmail.com, ffabriciosf, alineohashi\}@ufpa.br, \\ mar33vi@gmail.com, , jweyl@ufpa.br
}

\begin{abstract}
Fifth generation (5G) cellular networks will be the key element of a society that is becoming increasingly interconnected and digitalized. Applications adopted in many social and industrial sectors will require from $5 \mathrm{G}$ networks higher standards of availability and reliability. These requirements are leading operators to plan the deployment of protection schemes in the backhaul layer. In this context, our aim is to employ simulation to assess in a technical and economic way different backhaul protection schemes based on passive optical network (PON). The results indicates that the use of protection can increase the viability of $5 \mathrm{G}$ networks based in a PON backhaul supporting a hybrid fronthaul with fiber and copper.
\end{abstract}

\section{Introduction}

The evolution towards fifth generation $(5 \mathrm{G})$ cellular networks goes beyond meeting the demands of users requesting higher data rate transmission rates and mobile operators seeking to increase their profits and reduce energy consumption. With the deployment of $5 \mathrm{G}$, it is expected that the role of the mobile communication networks will be extended to ensure access to Internet services in the Internet of Things (IoT) concept, i.e., machine-to-machine solutions in industry, healthcare and education [Andrews et al. 2014]. This expansion has led 5G technology to serve a larger number of applications and to be transformed so that it can form the basis of an even more digitalized and ultraconnected society.

An even more digitalized society can be represented in terms of its large number of Internet-connection requests, e.g., every minute about 5 million videos are watched on YouTube and approximately 67,000 images are sent to Instagram servers [Ericsson 2014]. Other representations can be attributed to the profiles of users who are increasingly being integrated with smartphones, and to the generated network traffic, $70 \%$ of which, according to the Ericsson company is based on the requirements of indoor environments [Ericsson 2015]. In the context of an ultra-connected society, 5G users can be classified as extremely dependent on communication between users and services, i.e., a failure in infrastructure might cause serious and irreversible damage, e. g., incur heavy financial losses or even the loss of a life [Fernandez and Stol 2015]. 
To meet the foreseen demands in 5G networks, especially those of indoor users, several studies are investigating cost and energy-efficient network architectures between radio processing units and the antennas, i.e., the fronthaul layer, and between the network core and the radio processing units, i.e., the backhaul layer [METIS2020, Fiorani et al. 2014, Jaber et al. 2016, Farias et al. 2016, Tonini and Federico et al. 2017, Tonini et al. 2017, Fiorani et al. 2016, Fernandez and Stol 2017].

This work conducts a technical and economic analysis with the aim of assessing different protection schemes applied on a PON backhaul infrastructure used to feed $5 \mathrm{G}$ indoor fronthaul. In this way, we look for the best protection alternative aiming to reduce the damage and costs caused by lack of service in a digitalized society. A cost model based on the Markov Chain Monte Carlo (MCMC) simulation was implemented to obtain the results. I this way, simultaneous failures in the network can better modelled, which is not possible to do in a analytical aproach.

The remainder of this paper is divided into five sections. Section II outlines the details of the $5 \mathrm{G}$ architecture. Section III examines the cost models. Section IV discusses the case study employed for this investigation. Section V shows all the obtained results. Finally, the last section summarizes the main conclusions.

\section{Related works}

This section presents a set of works developed in recent years that deal with next generation mobile traffic transport alternatives, techno economic analysis of radio access networks and protection in PON networks.

The International Mobile Telecommunications system (IMT) has initiated research and technology trials for next generation mobile networks in 2013. The IMT vision for future mobile network as summarized by the mobile and wireless communications enablers for the twenty-twenty Information Society project (METIS2020), with aimed to propose technologies to support scenarios and demands of the 2020 and beyond digitized society, laying the foundation for 5G networks. The next generation mobile network will have a 1000 times the traffic volume demand, 10100 bigger user data rate, 10-100 more connected devices and sub-millisecond latency. In this context, its clear that the requirements of $5 \mathrm{G}$ networks will have a great impact on mobile transport infrastructures [METIS2020].

The main challenges of $5 \mathrm{G}$ transport networks and possible solutions for them in terms of capacity, flexibility and costs were investigated in [Fiorani et al. 2014] and [Jaber et al. 2016]. The first concludes that the use of dense-wavelength-division multiplexing in metropolitan networks combined with a transport network dedicated to small cells was pointed out as a solution to overcome the investigated challenges. The second presented a complete survey on the subject of 5G backhaul, indicating that a joint planning of backhaul and radio access networks (RAN) can enable the use of centralized-RAN (C-RAN) technologies, with can have gain attained when compared to the actual distributed RAN solutions, even with the "last mile" utilization of copper cables. In this context a hybrid optical/metallic indoor dedicated C-RAN solution supported by a WDM optical backhaul could be considered a good approach for $5 \mathrm{G}$ networks.

In order to economically investigate transport network architectures, paper [Farias et al. 2016] presents a comprehensive methodology to analyze the total cost of 
ownership (TCO) of several backhaul architectures based on fiber, microwave and copper. The authors considered two scenarios, i.e., a completely new deployment scenario (Greenfield) and an upgrade of legacy architecture (Brownfield). The work concludes that the use of passive optical networks (PONs) is the best backhaul approach in terms of energy efficiency, but due to the fiber high costs the best deployment strategy for Greenfield is PONs together with microwave links and to Brownfield results point PONs along the legacy copper infrastructure. Despite this, in [Tonini and Federico et al. 2017] an optimization strategy for implantation of a small cell fiberbased backhaul is presented, achieving reductions up to $50 \%$ in deployment costs for Greenfield and $70 \%$ for Brownfield, increasing viability of a fiber only infrastructure.

The papers [Tonini et al. 2017] and [Fiorani et al. 2016] present a design planning strategy for $5 \mathrm{G}$ using C-RAN, focusing on fronthaul. The first presented a strategy to reduce the cost of C-RAN indoor solutions minimizing the number of equipment required to deploy the network, achieving almost $60 \%$ cost reductions over the conventional deployment approach. The second presented a methodology for dimensioning the mobile network radio and transport segments for different transport solutions and evaluating the energy performance of these, showing that the deployment of indoor small cells in a heterogeneous scenario is better suitable for higher traffic levels and can consume less than half of the energy in a homogeneous case, as macro cells only. In addition, the results indicated that hybrid time and wavelength division multiplexing (TWDM) - PON is the best alternative for backhaul.

In regard of access network protection, the case of PONs has been vastly evaluated for fixed access networks. the papers [Fernandez and Stol 2015] and [Fernandez and Stol 2017] presents very complete formulations for economical unavailability analysis on PONs. The first focus on hardware failures and appoints that the duplication of components connected to major number of users increase the economically viability of PONs in an medium-long term operation for a urban scenario with high number of commercial users. The second considered also software failures, showing that the need of protection for commercial users is even bigger than the indicated by the first work.

\section{The 5G Architecture Analyzed - The C-Ran (Stacked)}

This study uses a hybrid fronthaul architecture consisting of optical fiber links and Cat5/Cat6 copper cables operating under the Gigabit Ethernet [Ericsson 2017, Huawei 2015].

The adopted solution is based on the stacking of base band units (BBUs) for creating a C-RAN. In a C-RAN the processing of transport and network layers of the Open Systems Interconnection model [Kurose and Ross 2012] is concentrated for a set of wireless cells with a distance up to $40 \mathrm{~km}$, offering a network with low costs, high reliability, low latency and large bandwidth [Macknofsky 2015]. 


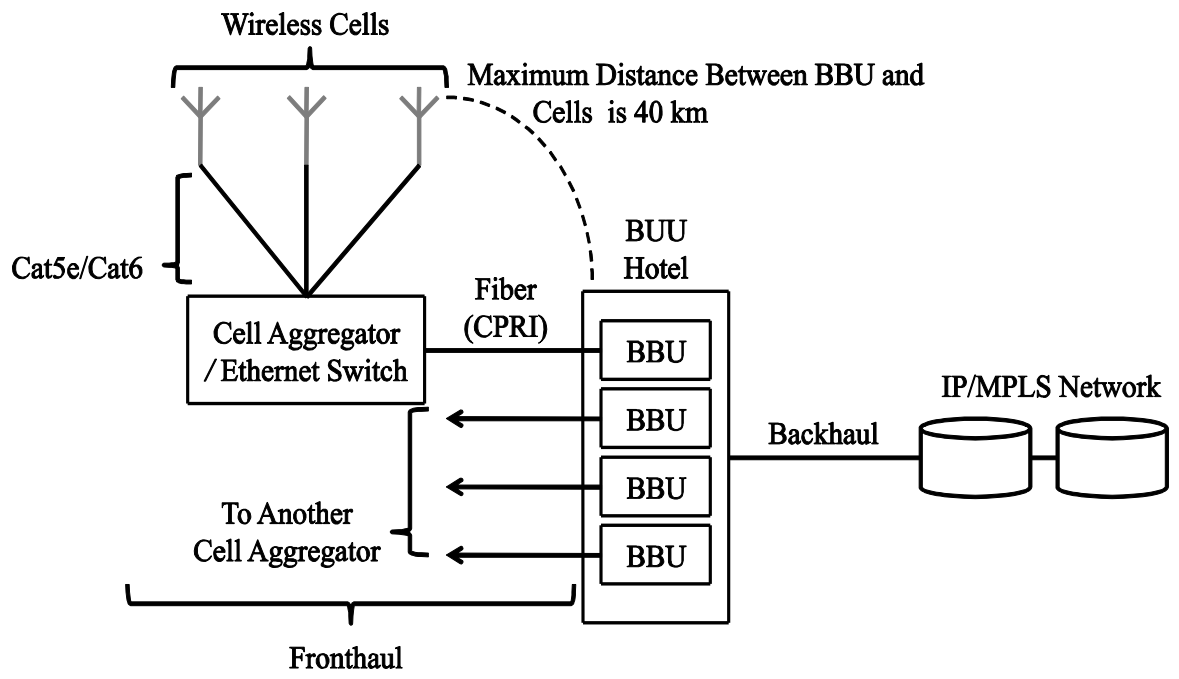

Figura. 1. The 5G architecture under consideration

Figure 1 shows the C-RAN architecture used for the 5G service technology adopted for this study, where an IP/MPLS network represents the backbone of the system. The communication links between the backbone and BBU hotel represent the backhaul framework, which is defined as a PON [Fernandez and Stol 2015]. The PON adopted consists of the following pieces of equipment: optical line terminal chassis (OLT chassis), optical line termination (OLT), remote node, passive splitter and optical network unit (ONU). The OLT chassis carries out the management of the network and makes the connection with the backbone, having several slots for OLT ports, which provides optical signal for the feeding fibers that serves the passive splitters within a remote node. In the splitters, the optical signal is replicated in accordance with the splitting rate and distribution fibers carry the signal to the ONUs, which makes the conversion of optical signal to an electric signal, establishing a link with the BBUs. The BBU hotel concentrates several BBUs which are connected by links of up to $40 \mathrm{~km}$ to one or more cell aggregators, which works in similar way to that of a gigabit Ethernet switch. Communication between the BBUs and cell aggregators is carried out via Common Public Radio Interface (CPRI) [Ericsson 2017, Huawei 2015]. Each aggregator must be connected to a set of cells with copper cable links (Cat5e/Cat6 models) using Gigabit Ethernet over CPRI [Ericsson 2017, Huawei 2015, IEEE Standard for Information Technology 2005], with rates and distance up to 2 Gbps and $100 \mathrm{~m}$, respectively. The set of links from the BBUs to the cells form the fronthaul for the $5 \mathrm{G}$ technology.

\section{The TCO Model}

The representation of the network dimensioning will be shown in this section, as well as the models employed for conducting the technical and economic analysis which was carried out from a total cost ownership model (TCO). The TCO is divided into two parts which take into account of both the network installation costs (CAPEX) and operational costs (OPEX). 


\subsection{Dimensioning of the Network}

This study aims to present a generic dimensioning model which can be easily adapted to the most different cases of density and distribution. It dimensions the network according to a Manhattan simple street model [Graham 1988], which includes square elements uniformly distributed in a square block.

Taking into account the need of representation of both the feeding and distribution levels of a PON, the model was first employed to distribute buildings on blocks and following this, to allocate the latter's in a square scenario. Figure 2 shows the dimensioning configuration used in this study, where $\mathrm{n}$ is the number of buildings beside a block, 1 is the distance between the centers of the two buildings, $\mathrm{N}$ is the number of blocks on one side of the square scenario and $l$ is the distance between the center of the two blocks and can be expressed by $L=n \times l$ [Fernandez and Stol 2015].

Assuming that the OLT chassis is in the office at the center of the scenario, the remote nodes in the middle of the blocks, the ONUs inside the buildings and that the distribution of the fibers is carried out in [Fernandez and Stol 2015], the dimensioning model can easily determine the number and distance of each equipment, the length of each trench and link, and the interconnections between the equipment and links in the scenario.

\subsection{CAPEX}

Once the network has been dimensioned and the features of the piece of equipment are defined, the CAPEX is given by (1):

$$
C A P E X=C_{\text {Fiber }}^{\text {Outdoor }}+C_{\text {Cab }}^{\text {Indoor }}+C_{\text {Pur }}^{E q}+C_{\text {Inst }}^{E q}
$$

where $C_{\text {Fiber }}^{\text {Outdoor }}$ is the total cost related to the outdoor fiber, $C_{\text {Cab }}^{\text {Indoor }}$ is the cost of indoor cabling, $C_{P u r}^{E q}$ is the purchase cost of the equipment and $C_{\text {Inst }}^{E q}$ is the installation cost of

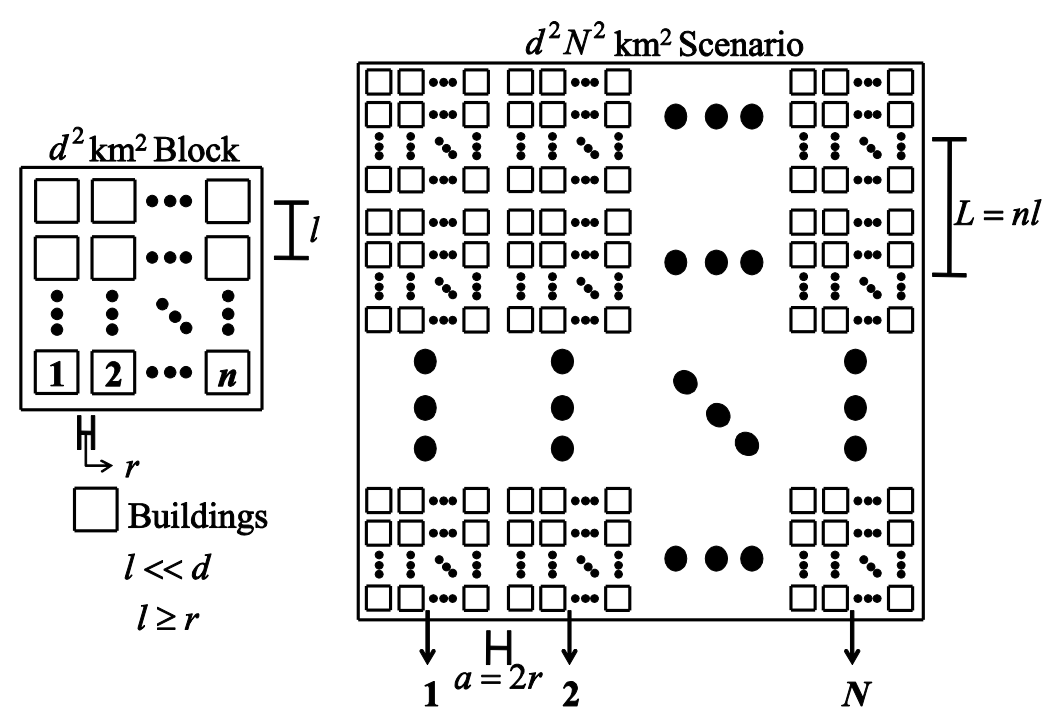

Fig. 2. Configuration of the outdoor environment 
the equipment. The cost of outdoor fiber $\left(C_{\text {Fiber }}^{\text {Outdoor }}\right)$ is determined by (2):

$$
C_{\text {Fiber }}^{\text {Outdoor }}=L g^{\text {Trench }} \times \operatorname{Pr}_{\text {Trench }}+L g^{\text {Fiber }} \times \operatorname{Pr}_{\text {Fiber }}
$$

where $L g^{\text {Trench }}, \operatorname{Pr}_{\text {Trench }}, L g^{\text {Fiber }}$ and $\operatorname{Pr}_{\text {Fiber }}$ are the length of the outdoor ducts for the fiber, the price of installing the ducts, the length of the outdoor fiber and the cost of purchasing and installing the fiber in the ducts respectively. The cost of the indoor cabling $\left(C_{\text {Cab }}^{\text {Indor }}\right)$ is determined by (3):

$$
C_{\text {Cab }}^{\text {Indoor }}=N_{\text {Indoor }, \text { cnx }}^{\text {Fiber }} \operatorname{Pr}_{\text {Indoor }, \text { cnx }}^{\text {Fiber }}+N_{\text {Indoor }, \text {,nx }}^{\text {Cat5e| }} \operatorname{Pr}_{\text {Indoor }, \text { cnx }}^{\text {Cat5e } 6}
$$

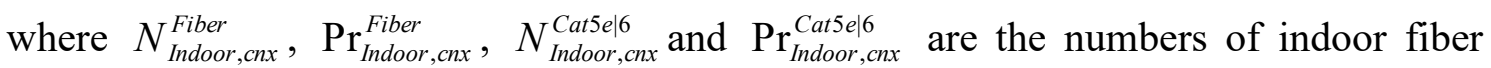
connections, the cost of the fiber per indoor connection, the number of indoor connections of Cat5e or Cat 6 cables and the cost of the Cat5e or Cat 6 cables per indoor connection, respectively. The cost, together with the purchase of the equipment $\left({ }_{P u r}^{E q}\right)$ is determined by (4):

$$
C_{P u r}^{E q}=\sum_{i} N_{i}^{E q} \operatorname{Pr}_{i}^{E q}
$$

where the $i$ index represents the different types of equipment and $N_{i}^{E q}$ and $\operatorname{Pr}_{i}^{E q}$ are the number of devices of type ${ }^{i}$ and the purchasing price of equipment of type ${ }^{i}$, respectively. Finally, the installation cost of the equipment $\left(C_{I n s t}^{E q}\right)$ is determined by (5):

$$
C_{\text {Inst }}^{E q}=\sum_{j}\left[T_{j}^{E q}+\frac{D_{j}^{E q}}{v}\right] \mathrm{Sal}
$$

where the $j$ index represents the different types of equipment that will be installed. $T_{j}^{E q}, D_{j}^{E q}, v$ and $\mathrm{Sal}$ are the installation time for equipment $j$, the distance of equipment $j$, the average speed and the salaries of the working teams.

\subsection{OPEX}

The OPEX is obtained from an operational analysis of the dynamics of the system, carried out from the modelling of the states of operation such as a Continuous Time Markov Chain (CTMC), with the definition of the state based on the numbers and types of faulty equipment, where the Markov reward model is used for the application of costs.

Equation (6) shows the OPEX when linked to a $k$ state:

$$
O P E X_{k}=C_{k}^{P e n}+C_{k}^{R p}+C_{k}^{\text {Ene }}+C_{k}^{\text {Leas }}
$$

where $C_{k}^{P e n}, C_{k}^{R p}, C_{k}^{\text {Ene }}$ and $C_{k}^{\text {Leas }}$ are the costs for repairs, fines and penalties, electric power consumption and floor space rent respectively, with regard to the $k$ state. The repair cost in the ${ }^{k}$ state $\left(C_{k}^{R p}\right)$ is determined by (7): 


$$
C_{k}^{R p}=\min (1, k)\left(\mathrm{Sal}+\operatorname{Pr}_{k^{\prime}} \eta\right)
$$

where $\operatorname{Pr}_{k^{\prime}}$ and $\eta$ are the purchase price of the equipment $k^{\prime}$ that must be repaired in the $k$ state and the factor of equipment repair costs, respectively, which range from 0 to 1. The term $\min (1, k)$ reflects the absence of repair costs in the case of an entirely functional network, represented by the state $k=0$. The penalty costs in the $k$ state ( $C_{k}^{P e n}$ ) are determined by (8):

$$
C_{k}^{\text {Pen }}=\left[\left(N_{k, \text { Ind }}^{\text {fail }}\right)^{\alpha} \operatorname{Pr}_{\text {Ind }}^{\text {pen }}+\left(N_{k, \text { Out }}^{\text {fail }}\right)^{\alpha} \operatorname{Pr}_{\text {Out }}^{\text {pen }}\right]
$$

where $\alpha, N_{k, \text { Ind }}^{\text {fail }}, \operatorname{Pr}_{\text {Ind }}^{\text {pen }}, N_{k, \text { Out }}^{\text {fail }}$ and $\operatorname{Pr}_{\text {Out }}^{\text {pen }}$ are the impact factor [17], the number of faulty indoor small cells, penalty for the lack of service of indoor cells, the number of faulty outdoor mobile cells and the penalty for the lack of service of outdoor mobile cell. The cost of electric power in the $k$ state $\left(C_{k}^{\text {Ene }}\right)$ is determined by (9):

$$
C_{k}^{E n e}=\operatorname{Pr}_{\mathrm{kWh}}\left(\operatorname{Tot}_{\mathrm{kWh}}^{E q}-F a l_{\mathrm{k}, \mathrm{kWh}}^{E q}\right)
$$

where $\mathrm{Pr}_{\mathrm{kWh}}, \operatorname{Tot}_{\mathrm{kWh}}^{E q}$ and $\mathrm{Fal}_{\mathrm{k}, \mathrm{kWh}}^{E q}$ represent the price of kilowatts per hour, the total amount of equipment in the network and the total amount of faulty equipment in the $\mathrm{k}$ state, respectively. Finally, the cost of floor space rent in the $k$ state $\left(C_{k}^{\text {Leas }}\right)$ is determined by (10):

$$
C_{k}^{\text {Leas }}=\operatorname{Tot}_{S} \operatorname{Pr}_{S}^{\text {Leas }}
$$

where $T_{0} t_{S}, \operatorname{Pr}_{S}^{\text {Leas }}$ are the total area occupied by indoor equipment and the cost of renting indoor space, respectively.

\section{Operation Simulator}

The TCO can be obtained by the sum of the CAPEX and OPEX, the first is obtained by network dimensioning, as for the second, knowing that the network is modeled as a CTMC the operational expenditures can be obtained by the sum of the product between the duration in time and the OPEX cost (Markov reward) related to each state.

The purpose of the operation simulator is to determine the duration time in each state of the chain. The operating methodology makes use of the information about the failure rates of functional equipment and the mean time to repair of faulty equipment (related to each operational state) to form a transition rate matrix. When this is applied to a cumulative analysis of CTMCs in a Monte Carlo simulation, it provides the average duration time for each state. The Simulator was implemented as in [Anders and Silva 2000].

\section{The Case Study}

This section outlines the case study which includes the metrics used to assess the protection framework used for the $5 \mathrm{G}$ architecture. The assessment was carried out in light of a techno-economic analysis based on the Markov reward model. This covered a 
high density urban setting [Machuca et al. 2011] based on Manhattan dynamic population [Moss and Qing 2012] of $64 \mathrm{~km}^{2}$, that contains 6400 6-floor buildings with 24 apartments per floor, where $63.21 \%$ of them are commercial buildings. A OLT chassis with a capacity of 72 gateways and a cell division rate of 1 to 32, was used for the backhaul architecture. With regard to the servicing of failures and the installation of the equipment, an average speed of $20 \mathrm{~km} / \mathrm{h}$ was assumed during transport of the repair/installation teams to the point of failure or installation. In addition, for financial reasons, a cost unit was employed based on the price of an indoor small cell, which at the time when this study was carried out cost US\$ 300 [Yaghoubi et al. 2018].

The salaries for the working teams, price of kilowatts per hour and penalty cost for lack of communication through indoor and outdoor small cell, are assumed to be $0.63 \mathrm{UC} / \mathrm{h}, 3.33 \times 10-5 \mathrm{CU}, 0.05 \mathrm{CU} / \mathrm{h}$ and $1.52 \mathrm{CU} / \mathrm{h}$, respectively. The two first are based on a European scenario cost and the lasts are based on the variation over the penalty costs presented in [Fernandez and Stol, 2015]. Finally, the following points were assumed for the network: operation of 10 years, $50 \%$ of the population as subscribers to $5 \mathrm{G}$ and $40 \%$ of active $5 \mathrm{G}$ users during the peak traffic periods. Where the two last are based on extrapolations of $4 \mathrm{G}$ networks data from Cisco and European EARTH project.

The 5G architecture that was implemented is shown in Figure 3 and ensures both indoor and outdoor coverage. For the first each commercial building has a BBU hotel linked to the PON backhaul and the hybrid fiber/copper fronthaul, which is spread within the building. For the second it is assumed that some buildings located along parallel diagonal lines which cross the scenario, have a small outdoor mobile cell (pico cell) at their diagonal top which is connected by optical links to a BBU, thus forming a chessboard pattern of outdoor cells with regard to the buildings and ensuring a line of sight is provided to the outdoor user [Lopes et al. 2015]. In this way, in peak traffic data rates of $1 \mathrm{Gbps}$ and $144 \mathrm{Mbps}$ can achieved by indoor and outdoor users, respectively.

Four architectures were included for the PON backhaul : (a) unprotected, (b) with fiber duplication at the feeding level, (c) with interconnection of the OLTs and fiber duplication at the feeding level, (d) with interconnection of the OLTs and fiber duplication of the feeding and distribution levels. All the architectures are illustrated in Figure 4. The first is the basic PON described in section 3. The second duplicates the feeder fibers using a optical switch that will operate in case of failure of main fiber. The third considers a cross-connection between pairs of OLT chassis using splitters and switches. The last duplicates the distribution fiber using also a optical switch and supposing that each ONU has two optical inputs.

The parameters for the PON backhaul equipment such as failure rates, installation time, repair time and costs were taken from [Machuca et al. 2012] and [OASE 2011], whereas the parameters for the fronthaul components were based on equipment available in the actual telecom market. Table I shows the operating and installation parameters included for all equipment of the network. 


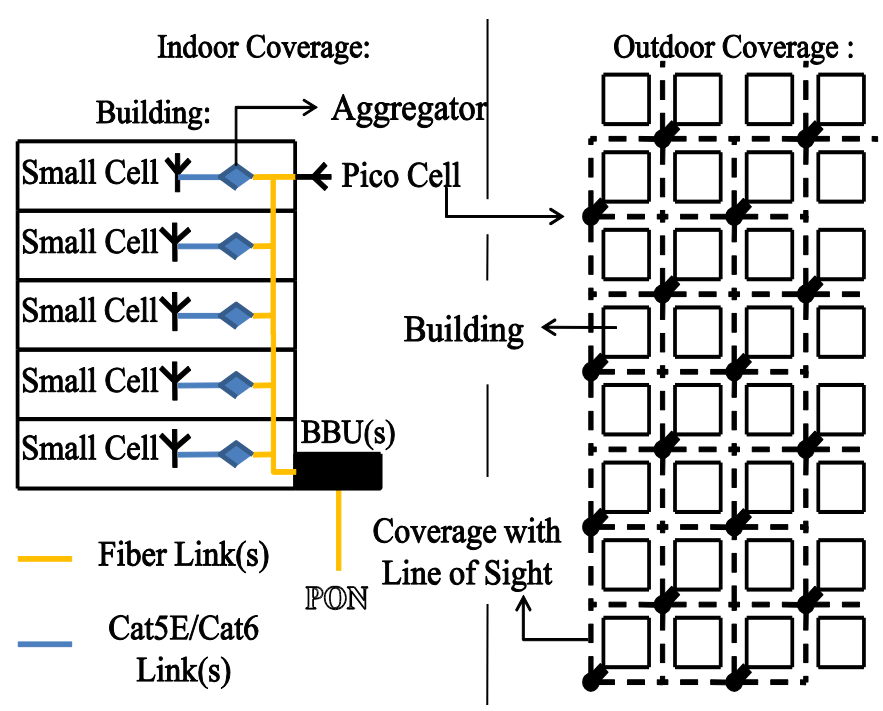

Fig. 3. The proposed fronthaul architecture with the indoor and outdoor distribution of mobile cells.

(a)

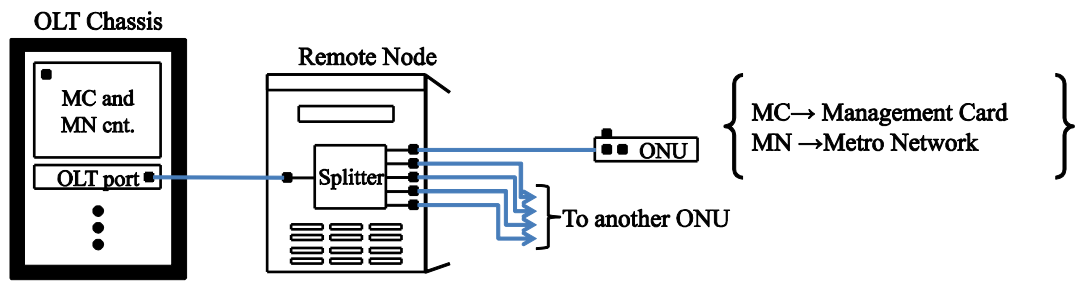

OLT Chassis

(b)
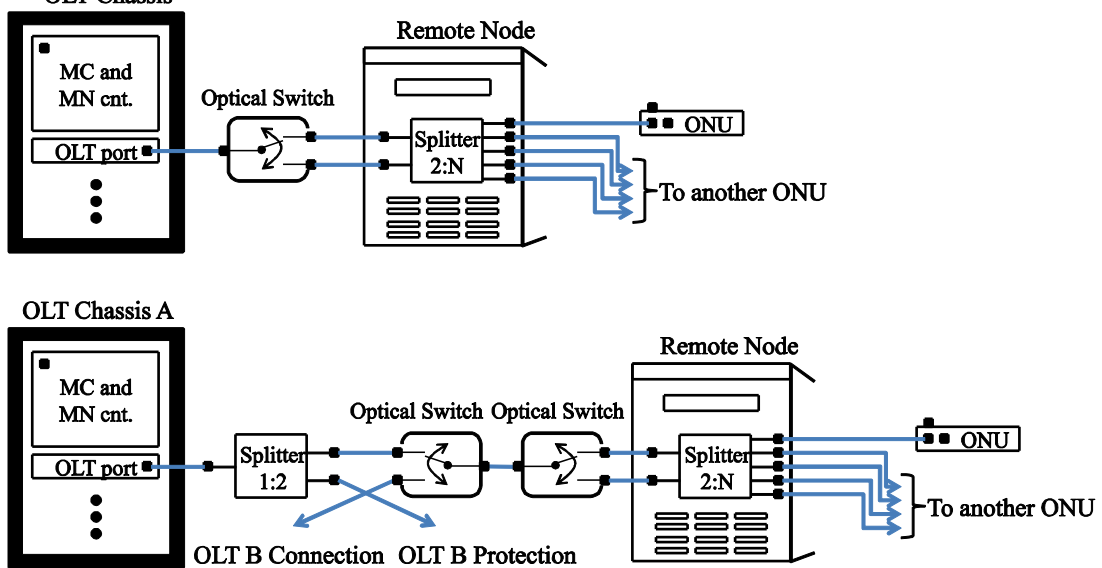

(d)

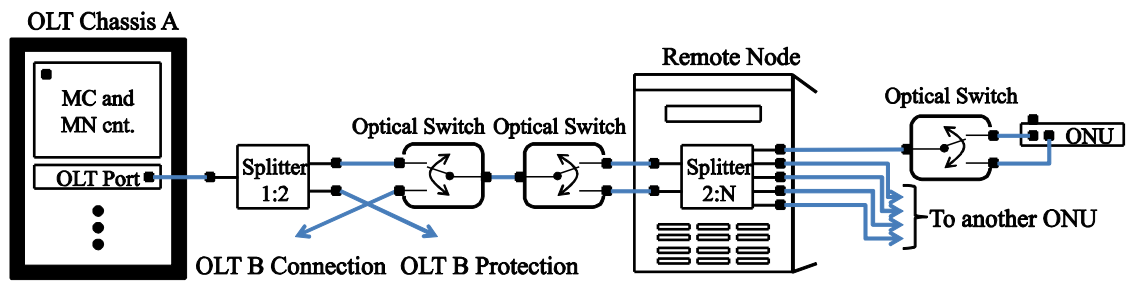

Fig. 4. Proposed backhaul architecture. (a) Without protection, (b) with duplication of the feeding level, (c) with interconnection of the OLT and duplication of the feeding level, (d) with interconnection of the OLT and duplication of the feeding and distribution levels 
Table 1. Parameters For The Equipment

\begin{tabular}{|c|c|c|c|c|c|}
\hline Equip. & $\begin{array}{l}\text { Cost } \\
(\mathbf{C U})\end{array}$ & $\begin{array}{c}\text { Installati-on } \\
\text { Time (min) }\end{array}$ & $\begin{array}{c}\text { Failure } \\
\text { Rate } \\
\text { (FIT) }\end{array}$ & $\begin{array}{c}\text { Mean } \\
\text { Time of } \\
\text { Repair (h) }\end{array}$ & $\begin{array}{c}\text { Power } \\
\text { Con- } \\
\text { sumption } \\
\text { (W) }\end{array}$ \\
\hline Small Cell & 1 & 4 & 777 & 1 & 30 \\
\hline $\begin{array}{l}\text { Small Cell } \\
\text { Aggrega-tor }\end{array}$ & 1 & 20 & 3333 & 1 & 150 \\
\hline BBU & 2.33 & 48 & 6451 & 1 & 165 \\
\hline $\begin{array}{c}\text { Indoor } \\
\text { Cat5e|6 } \\
\text { connection }\end{array}$ & 0.33 & - & $10.6 / \mathrm{m}$ & 1 & 0 \\
\hline $\begin{array}{c}\text { Indoor } \\
\text { fiber } \\
\text { connection }\end{array}$ & 0.66 & - & $10.6 / \mathrm{m}$ & 7 & 0 \\
\hline ONU & 1.17 & 60 & 256 & 1 & 5 \\
\hline Splitter & $\begin{array}{l}0.16 \\
/ \text { port }\end{array}$ & 10 & 120 & 1 & 0 \\
\hline $\begin{array}{l}\text { Remote Node } \\
\text { Chassis }\end{array}$ & 2.33 & 10 & 667 & 1 & 0 \\
\hline OLT port & 25.33 & 10 & 1075 & 1 & 1197 \\
\hline OLT chassis & 15 & 30 & 500 & 1 & 200 \\
\hline $\begin{array}{l}\text { Optical } \\
\text { switch }\end{array}$ & 0.16 & 10 & 200 & 2 & 0 \\
\hline $\begin{array}{l}\text { Outdoor fiber } \\
\text { trench }\end{array}$ & $\begin{array}{c}433.5 / \mathrm{k} \\
\mathrm{m}\end{array}$ & - & $\begin{array}{l}2380 \\
/ \mathrm{km}\end{array}$ & 7 & 0 \\
\hline
\end{tabular}

\section{Results}

Figure 5 shows the TCO for the PON backhaul architectures displayed. It is clear that Architecture D is more expensive and that Architectures B and C lead to lower costs than Architecture A, which is unprotected, with the cost of Architecture C being slightly lower. With regard to CAPEX, it was noted that the architectures of protection - B and C

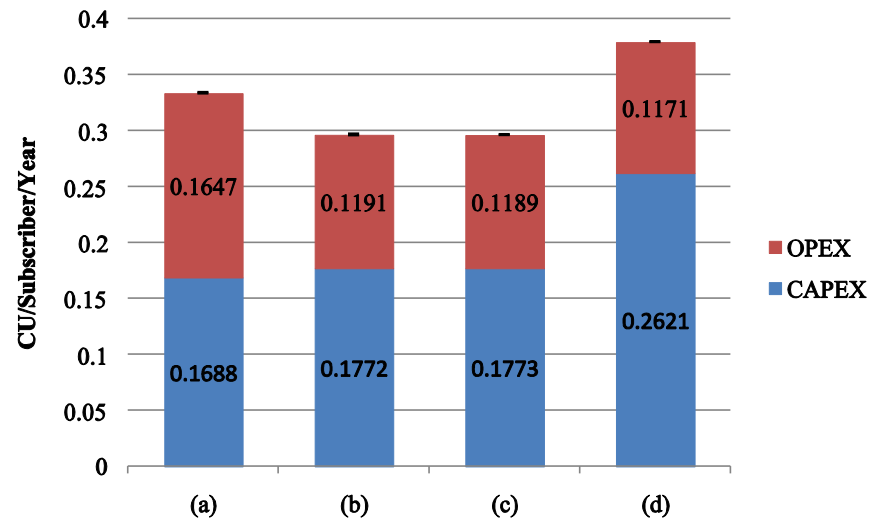

Fig. 5. TCO of the $5 G$ network in terms of CAPEX and OPEX including the various PON backhaul architectures shown in the case study. 
- require less funding for installation, while Architecture D requires a considerable investment. With regard to OPEX it should be noted that all the protection architectures have lower costs, with reductions of approximately $0.4 \mathrm{UC} / \mathrm{Subscriber} / Y$ ear with regard to Architecture A. The lowest OPEX was obtained by Architecture D, which, in contrast, requires a larger investment in CAPEX and thus accounts for the fact that its installation is not feasible.

Figure 6 presents in terms of percentage the cost composition of CAPEX and OPEX for all the backhaul architectures considered on the case study. With regard to CAPEX, shown in Figure 6 (a), it is noted that fiber costs composes the major part of it and that this is even more evident in protected architectures. Moreover, the cost of purchasing equipment has also a bigger participation in the CAPEX, due to the increased number of devices within the indoor environment and the costs with cabling reach between $5 \%$ and $8 \%$ of the CAPEX, depending on the PON backhaul architecture.

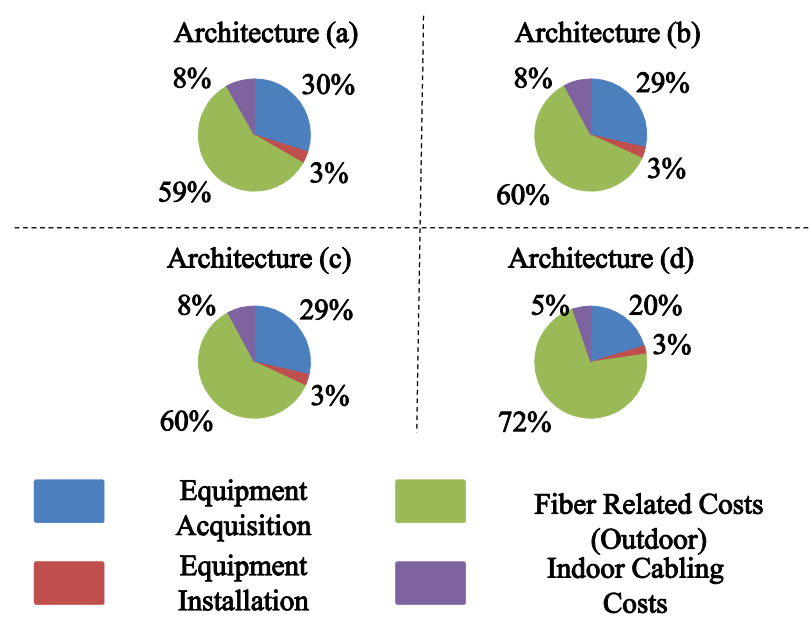

(a) CAPEX

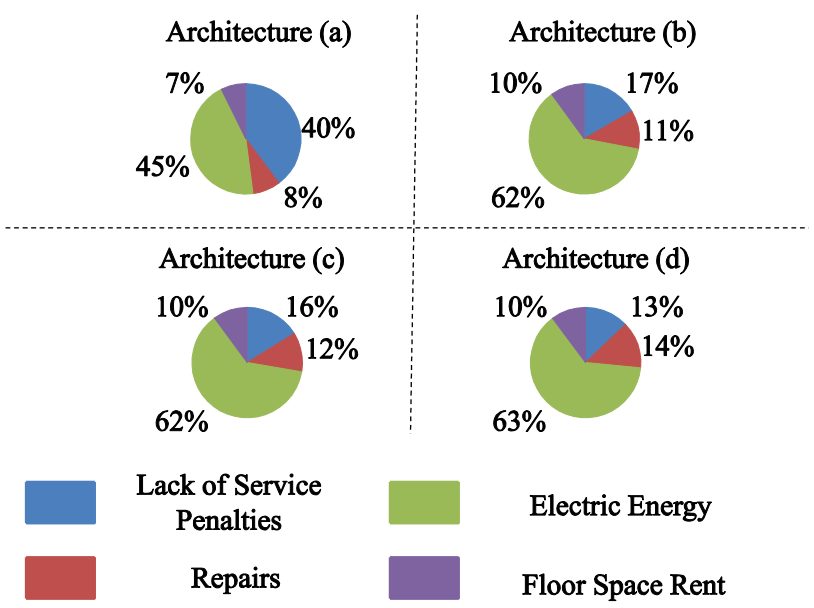

(b) OPEX

Fig. 6. Contribution in percentage of CAPEX or OPEX operations considering the PON backhaul architectures in the case of study 
In addition, it is worth noting that the installation cost maintains always approximately $3 \%$ of participation in CAPEX. With regard to OPEX, shown in Figure 6 (b), it was found that the highest expenditure participation was electricity and that in Architecture A the costs with penalties for lack of service amounted to almost as much as the electricity. However, this was not the case for Architectures B, C and D, where the costs for penalties are greatly reduced. In contrast, the repair costs increase proportionally and can reach as much as $14 \%$ in Architecture D. Finally, the variation of cost participation of floor space rent is result of other OPEX components variations, once the value of the cost is the same for all analyzed architectures.

\section{Conclusion}

This study has conducted a technical and economic analysis focused on different protection solutions for passive optical networks in a backhaul deployment for 5G networks. Relying on a geometric dimensioning of the network and on a cost estimation model based on CTMC solved by Monte Carlo simulations using the Markov reward model. The obtained results suggest that the use of protection schemes can increase the economic feasibility of 5G networks based on PON backhaul and show that the penalty costs of an unprotected network, represent $40 \%$ of the OPEX, making it only lower than the expenditure of electric power consumption. In addition, it is clear that the protection architectures have managed to increase the indices of reliability and availability by reducing the expenses incurred for penalties by up to $13 \%$ of the OPEX, which suggests an increase of service availability of $0.999 \%$ in the unprotected case and $0.9999 \%$ for the case that is protected. This provides evidence that the protection architectures can or should be adopted to meet the required conditions for the service availability needed by the 5G. Finally, in the operating time of 10 years, it was found that duplicating the levels of feeding and distribution (as in Architecture D) results in a financial loss. However, for the duplication of the feeding fiber, either isolated or connected to the interlinking of OLT (Architectures B and C), there is a financial gain and the protection architecture makes a financial return through economies, owing to the reduction of the penalties. In future studies, we plan to detail the utilized simulator, apply a traffic model to better understand the users needs, provide comparison with another tecno-echonomic models and use geographical scenarios.

\section{Acknowledgment}

The authors would like to express their thanks to the Applied Electromagnetism Laboratory (LEA) and Extreme Programming Laboratory (LABEX), both affiliated to the Federal University of Pará (UFPA). In addition, we also thanks to the scientific and technological initiation program (PIBIC), the doctor researcher support program (PRODOUTOR) and the UFPA electric engineering post graduation program (PPGEE).

\section{References}

Andrews, J. G., Buzzi, S., Choi W., Hanly, S. V., Lozano, A., Soong, A. C. K. and Zhang, J. C. "What will 5g be?," IEEE Journal on Selected Areas in Communications, vol. 32, pp. 1065-1082, Junho 2014.

Ericsson, "5g: what is it for?," white paper, Ericsson AB, Stockholm, Sweden, 2014. 
Ericsson, "Small cell services: Network performance where and when it matters," white paper, Ericsson AB, Stockholm, Sweden, 2015.

Fernandez, A. and Stol, N. "Capex and opex simulation study of cost-efficient protection mechanisms in passive optical networks," Opt. Switch. Netw., vol. 17, pp. 14-24, July 2015.

METIS2020 "Metis deliverable D1.1: scenarios, requirements and KPIs for 5G mobile and wireless systems," 2013.

Fiorani, M., Monti, P., Skubic, B., Martensson, J., Valcarenghi, L., Castoldi, P. and Wosinska, L. "Challenges for 5g transport networks," in 2014 IEEE International Conference on Advanced Networks and Telecommuncations Systems (ANTS), pp. 1-6, Dec 2014.

Jaber, M., Imran, M., Tafazolli, R. and Tukmanov, A. "5G Backhaul Challenges and Emerging Research Directions: A Survey," in IEEE Access, vol. 4, pp. 1743-1766, 2016.

Farias, F. et al., "Cost- and energy-efficient backhaul options for heterogeneous mobile network deployments," Photonic Network Communications, vol. 32, no. 3, pp. 422437, 2016.

Tonini, Federico, et al. "Benefits of joint planning of small cells and fiber backhaul in 5G dense cellular networks." Communications (ICC), 2017 IEEE International Conference on. IEEE, 2017.

Tonini, F., Fiorani, M., Furdek, M., Raffaelli, C., Wosinska, L. and Monti, P. "Radio and Transport Planning of Centralized Radio Architectures in 5G Indoor Scenarios," in IEEE Journal on Selected Areas in Communications, vol. 35, no. 8, pp. 18371848, Aug. 2017.

Fiorani, M., Tombaz, S., Farias, F., Wosinska, L. and Monti, P. "Joint design of radio and transport for green residential access networks," IEEE J. Sel. Areas Commun., vol. 34, no. 4, pp. 812-822, Apr. 2016.

Fernandez, A. and Stol, N. "Economic, Dissatisfaction, and Reputation Risks of Hardware and Software Failures in PONs," in IEEE/ACM Transactions on Networking, vol. 25, no. 2, pp. 1119-1132, April 2017.

Ericsson, "Ericsson radio dot system redefining in-building small cells," white paper, Ericsson AB, Stockholm, Sweden, 2017.

Huawei, "Atomcell9.0 lampsite solution," white paper, HUAWEI TECHNOLOGIES CO., LTD., Republic of China, 2015. 
Kurose, J. F. and Ross, K. W. Computer Networking: A Top-Down Approach (6th Edition). Pearson, 6th ed., 2012.

Macknofsky, G. "Understanding the basics of cpri fronthaul technology," application note, EXFO Inc., Quebec, Canada, 2015.

IEEE Standard for Information Technology - Telecommunications and Information Exchange Between Systems - Local and Metropolitan Area Networks - Specific Requirements Part 3: Carrier Sense Multiple Access with Collision Detection (CSMA/CD) Access Method and Physical Layer Specifications," in IEEE Std 802.32005 (Revision of IEEE Std 802.3-2002 including all approved amendments), vol., no., pp.1-2695, 9 Dec. 2005

Graham, R. L. The shortest network problem, 1988.

Dixit, A., Mahloo, M., Lannoo, B., Chen, J., Wosinska, L., Colle, D. and Pickavet, M. "Protection strategies for next generation passive optical networks -2," in 2014 International Conference on Optical Network Design and Modeling, pp. 13-18, May 2014.

Anders, G. J. and Silva, A. M. L. "Cost related reliability measures for power system equipment," IEEE Transactions on Power Systems, vol. 15, pp. 654-660, May 2000.

Machuca, C. M., Chen, J., Wosinska, L., Mahloo, M. and Grobe, K. "Fiber access networks: Reliability and power consumption analysis," in 15th International Conference on Optical Network Design and Modeling - ONDM 2011, pp. 1-6, Feb 2011 .

Moss, M. L. and Qing, C. "The dynamic population of manhattan," tech. rep., New York University, USA, 2012.

Yaghoubi, F., Mahloo, M., Wosinska, L., Monti, P., Farias, F. S. and Costa, J. C. W. A. "A techno-economic framework for 5G transport networks," IEEE Wireless Communications Magazine, 2018, in press.

Lopes, A. R. M., Farias, F. S. and Costa, J. C. W. A. "Evaluation of the energy impact on indoor small cells and backhaul," International Journal of Future Computer and Communication, vol. 4, pp. 151-159, June 2015.

Machuca, C. M., Chen, J. and Wosinska, L. "Cost-efficient protection in TDM pons," IEEE Communications Magazine, vol. 50, pp. 110-117, August 2012.

OASE, Technical Assesment and Comparison of Next-Generation Optical Access System Concepts, october 2011. 